\title{
LAS AMARGURAS DE UN INTELECTUAL REPUBLICANO EN CHECOSLOVAQUIA ${ }^{1}$
}

\author{
GUSTAVO MONGE \\ (Corresponsal de la Agencia EFE en Praga)
}

\begin{abstract}
Resumen
El historiador, periodista y profesor coruñés Francisco Fariña, del que ahora se cumple el 130 aniversario de su natalicio llegó a Checoslovaquia en 1933. Colaboró con el Instituto Español e Iberoamericano y las Facultades de Filosofía y Letras de la Universidad Carolina de Praga y Universidad Masaryk de Brno. Sus alumnos jugaron un papel clave para elevar los estudios hispánicos e iberoamericanos a rango universitario. La situación política en España y celotipias profesionales enturbiaron su estancia en el país centroeuropeo y le obligaron a exiliarse a Alemania, donde falleció en 1955.
\end{abstract}

Palabras claves: Francisco Fariña; filología hispánica; Checoslovaquia.

\section{The Bitterness of a Republican Intellectual in Czechoslovakia}

\begin{abstract}
The historian, journalist and professor from La Coruña Francisco Fariña, of whom we now celebrate the 130th anniversary of his birth, came to Czechoslovakia in 1933. He collaborated with the Spanish and Ibero-American Institute and the Schools of Languages of Charles University in Prague and Masaryk University Masaryk in Brno. His students played a key role in Spanish and Ibero-American studies becoming a university degree. The political situation in Spain and professional jealousy clouded his stay in the Central European country and forced him to exile in Germany, where he died in 1955.
\end{abstract}

Keywords: Francisco Fariña; Spanish; Iberoamerican studies; Czechoslovakia.

\section{Antes de llegar a Checoslovaquia}

Francisco Javier Fariña Alonso nació en La Coruña el 12 de octubre de 1891, fiesta del Pilar y Día de la Hispanidad, algo simbólico para un patriota. Se licenció en Historia por la Universidad de Santiago de Compostela en septiembre de 1932. Y entonces, con 41 años, emprendió un proyecto pedagógico ambicioso: la Junta de Relaciones Culturales, ${ }^{2}$ destinada a modernizar la enseñanza del español, le envió

1 Nota de la redacción: Para el personaje de F. Fariña véase: Lubomír Martinec, Ibero-Americana Pragensia 28, Praga 1994, pp. 169-171. Para las personas que trabajaron en la Facultad de Filosofía y Letras de la Universidad Carolina mencionados en el presente texto, como el mismo F. Fariña o R. J. Slabý, también hay materiales en el Archivo de la Universidad Carolina.

2 Órgano del Ministerio de Estado (o de Relaciones Exteriores) durante la II República. Se encargaba, entre otras cosas, de propagar el idioma y cultura españolas en el extranjero, una misión que hoy lleva a cabo la red internacional del Instituto Cervantes. 
a Checoslovaquia, un país con poca tradición en esta lengua, a pesar de los intensos vínculos del pasado.

Cabe preguntarse por qué tardó tanto en licenciarse. Había sido alumno brillante del Instituto General y Técnico de La Coruña, ${ }^{3}$ donde obtuvo premio en un concurso convocado para celebrar la primera edición del Quijote de Cervantes en 1605. Con 17 años consiguió el título de profesor de educación elemental. Asistió en 1910 a clase en las Facultades de Derecho y de Filosofía y Letras en la Universidad Central de Madrid. Y en 1913 interrumpió estudios para hacer el servicio militar.

A partir de 1917 colaboró en la redacción del semanario La España Económica y Financiera, hasta llegar a dirigir esta publicación desde 1924, según dice su currículo. Entre medias, en 1920, se hizo miembro del Instituto de Reformas Sociales, creado en 1903 por el gobierno español para que estudiara y propusiera leyes y decretos que mejorasen la vida y las condiciones laborales de las clases obreras. Su interés por las políticas sociales y el periodismo le llevó a fundar la revista Orientaciones, que tuvo una corta vida y fue antecesora de la publicación francesa Le Mois.

En 1931 el Gobierno republicano español le nombró jefe del Departamento IV del Ministerio de Trabajo, dedicado a inmigración. Luego pasó al Departamento II, dedicado a la fuerza laboral, agenda que tiene hoy encomendada el Instituto Nacional de Empleo (en adelante sólo INEM). Ahí también se dedicó a la problemática de los trabajadores extranjeros en España. Entonces conoció a la que convertiría después en su mujer, la checoslovaca Gertrudis Hille, que hacía gestiones en el Ministerio para obtener un permiso de trabajo o una licencia para abrir un salón de moda en la capital de España. Este fue su bagaje antes de licenciarse por la Universidad de Santiago de Compostela en 1932. Su currículo nos dice que ese año ejerció de secretario de la Junta para Establecer Relaciones Culturales del Ateneo Científico y Literario de Madrid.

Se presentó en diciembre de 1932 a un concurso de la Central de Estudios Históricos, que dependía de la Junta de Relaciones Culturales del Ministerio de Asuntos Exteriores, para ocupar un lectorado de lengua española en la Universidad Popular de Komenský en Brno. Brno fue para Fariña la puerta de entrada en Checoslovaquia. Aquí compaginó su labor docente con el estudio, en Praga, de organismos dedicados a las políticas sociales: un trabajo comisionado y remunerado por la Junta para Ampliación de Estudios e Investigaciones. ${ }^{4}$ Fariña quiso además mantener en el país centroeuropeo sus vínculos con el periodismo, y solicitó al Ministerio de Asuntos Exteriores en Praga una acreditación especial como corresponsal. Esto le iba a permitir además viajar más barato en los trenes. ${ }^{5}$ Una nota de la diplomacia checoslovaca fechada en 1939 constata que Fariña fue corresponsal de periódicos españoles y, como tal, adquirió abonos anuales de transporte con derecho a viajar en $2^{\mathrm{a}}$ clase en toda la red de ferrocarriles nacionales checoslovacos, por un coste anual de 870 coronas, lo que equivalía al sueldo medio mensual de un empleado.

\footnotetext{
Archiv bezpečnostních složek Praha (en adelante sólo ABS), Studijní ústav Ministerstva vnitra (en adelante sólo SÚMV), sección II. y III., signatura [233-2-1/32-34].

ABS, fondo SÚMV, sección II. y III., signatura [233-2-1/32-34]

Ibidem.
} 
Llevado además de su patriotismo, quiso combatir leyendas negras y otras imprecisiones históricas que, en descrédito de España, habían aflorado y perpetuado en ambientes anglosajones y germánicos. En vez de capa, concha y báculo de peregrino, para acometer esa misión llegó armado de vitalismo, espíritu combativo y vehemencia, aunque algo menos pertrechado -como veremos- en recursos diplomáticos.

Esta es la primera semblanza sobre Fariña, lo que me llena de orgullo, a la vez que soy consciente de sus limitaciones. Además de entrevistas con sus familiares, he utilizado los "escritos apologéticos" del español, por llamar de algún modo a la abundante correspondencia diplomática, casi siempre dirigida a reivindicar sus méritos y un tratamiento más justo hacia su persona. También he cedido la palabra a los que le conocieron en los albores del hispanismo checoslovaco moderno, el marco académico en el que situamos su vida. Es decir, que me he apoyado en la metodología de la historia oral. Dicho esto, oigamos la voz de una experta que nos introduce en el contexto universitario en que se movió el personaje.

"El estudio sistemático del español tiene su origen en el marco de la filología románica, que se empieza a estudiar en el siglo XIX", ${ }^{6}$ pero no sale del cascarón de las lenguas romances hasta bien entrado el XX.

Después de la II Guerra Mundial en cuatro universidades checoslovacas -en Praga, Brno, Olomouc y Bratislava- se introduce el estudio de la Filología hispánica que se desarrolla de manera significativa, aumentándose su contenido europeo en la dimensión hispanoamericana. ${ }^{7}$

Aquí es donde juega un importante papel nuestro personaje, como reconoce Anna Mištinová. Esta valoración de la lingüista checoslovaca sirve para enmarcar los desafíos que se le presentaron. Se trataba de impulsar un saber relativamente desconocido, exótico, sin identidad propia en las aulas de educación superior, y -en buena medida- en manos de entusiastas. Había mucho que sistematizar.

Ese desconocimiento, y no sólo en el aspecto lingüístico, era recíproco. El historiador Ramón Menéndez Pidal, presidente del Comité Hispano-Eslavo, fundado en 1931, afirmó el 14 de enero de aquel año en un círculo de intelectuales:

Hay un grupo importante de pueblos del que tenemos, hasta ahora, escaso conocimiento y que sin embargo, merece nuestro mayor interés y nuestro solícito estudio. Nos referimos a los pueblos eslavos, que con más de 140 millones de individuos, constituyen un tercio de la población de Europa. La raza eslava, con Bulgaria,

6 Anna MIŠTINOVÁ, "Enseñanza del español en el sistema educativo checo: aspectos metodológicos y factores extra-lingüísticos", in: José María Izquierdo, Olga Juan Lázaro, Juan Pedro De Basterrechea, Montserrat Alonso, Rocío Prieto, Ana Mochón, Hyosang Lim y Werner Altmann, Actas del I Congreso internacional de FIAPE: "El español, lengua del futuro", Toledo 2005, p. 1

7 MIŠTINOVA, "Enseñanza", p. 1. 
Checoslovaquia, Polonia, Rusia -no sólo la Rusia de hoy, sino también la de ayer y la de mañana-y Yugoeslavia, es un mundo al que no podemos permanecer extraños. ${ }^{8}$

Días después, el 20 de enero, se creó el citado comité "para fomentar las relaciones espirituales y económicas de España con los países eslavos".

Fariña, cuyo traslado a Praga para una aventura universitaria contó con la venia de Menéndez Pidal, estaba imbuido de espíritu demócrata y republicano, sin el marchamo antirreligioso que caracterizó ese período convulso, que fue preludio de la Guerra Civil. El problema es que, por las circunstancias particulares que atravesó España, lejos de poder ejercer pacíficamente su docencia, Fariña se vio en medio de un fuerte oleaje. Y esto le obligó a nadar a contracorriente para no hundirse. A ello se sumaron los problemas causados por las celotipias profesionales y la nacionalidad alemana de Gertrudis, su mujer, en un país donde esa minoría quedó en entredicho tras la firma del Tratado de Múnich de 1938, cuando Alemania se anexionó un tercio del territorio checoslovaco.

Pero eso ocurrió después. Al llegar a Praga en 1933, también para unir su destino en matrimonio con Gertrudis -en una conocida iglesia praguense-, es muy posible que Fariña augurara una estancia feliz, en un país que atravesaba por momentos de desarrollo y prosperidad. Aquí podría dar rienda suelta a sus vuelos universitarios, a la vez que asimilaba las mejores prácticas de los entes de previsión checoslovacos.

\section{Impulsor del hispanismo}

Brno fue, como señalamos, puerta de entrada de Fariña en el mundo académico checoslovaco. Concretamente, en un lectorado de español en la Facultad de Filosofía y Letras de la Universidad Jan Evangelista Purkyně. En la metrópolis moravia también impartió clases en una academia de comercio, una de las múltiples opciones de formación profesional que ofrecía, y sigue ofreciendo, la enseñanza secundaria checa. Pero Brno se le queda pequeño pronto, y además tiene que alimentar a una familia que crece.

En junio de 1934, año y medio después de llegar, hace recapitulación de los primeros meses. ${ }^{9}$ Fariña ha abierto una brecha en Praga, gracias al nuevo lectorado de español en la Facultad de Filosofía y Letras de la Universidad Carolina. Aquí entró en contacto y forjó amistad con los profesores de Filología Francesa Karel Titz (1880-1940) y Maxmilián Křepinský (1875-1971). Era lógico, pues Fariña hablaba y traducía la lengua gala. Esta especialidad, a diferencia del español, estaba plenamente consolidada en la cátedra de Lenguas Romances. Otro nombre conocido de entonces era Václav Černý, catedrático de Literatura Comparada, y que ayudó al coruñés en momentos de crisis.

8 Ústav TGM v Praze, Archivo del Instituto Tomáš Garrigue Masaryk (en adelante sólo ÚTGM), fondo TGM, R-Republika 1918-1937, España, caja 528, Memoria del Comité Hispano-Eslavo, Madrid 1931.

9 AMAEC, República, Fondo de Barcelona, RE-6O, carta de Francisco Fariña, a Lorenzo Luzuriaga, secretario general de la Junta de Relaciones Culturales (Praga, 1 de junio de 1934). 
En la Vysoká škola obchodní (Escuela Comercial Superior) de Praga, en cierta medida antecesora de la Vysoká škola ekonomická (Escuela Superior de Economía), dio clases de lengua y dictó conferencias sobre cultura española y la obra de España en América.

Labor digna de notarse, pues los manuales que se estudian en muchos centros de segunda enseñanza todavía insisten en la barbarie de nuestra colonización y en la afirmación de que la cultura española era inferior a la que en ellos existía; y además debemos subrayar la importancia de esta obra rectificadora, porque de esta Escuela salen los elementos que dirigirán la vida económica de Checoslovaquia y los técnicos de la Administración y de las representaciones diplomáticas, cuya influencia en la opinión pública es bien notoria..$^{10}$

Después de Praga y Brno, Fariña inició su prometedora actividad en Bratislava y Zlín, donde sembró nuevas semillas entre los jóvenes que sentían inclinación por la lengua de Cervantes.

El catedrático Josef V. Polišenský (1915-2001), uno de los principales referentes del hispanismo checo moderno, se refiere a Fariña en sus memorias. ${ }^{11}$ El profesor gallego, si bien no era una estrella rutilante en el firmamento de la filología, supo inculcar con sus escritos y conversaciones el amor al idioma y cultura de su país. Y ayudó a los alumnos, por ejemplo, a entender la situación que atravesaba la II República. Polišenský brilló después con sus investigaciones sobre las relaciones históricas entre la Corona de Bohemia y de España. Y vio en Fariña un impulsor del proceso que culminó en la mayoría de edad de la Filología Hispánica en las facultades checas durante la posguerra. Un mérito que, por la evolución de los acontecimientos políticos, nunca le fue reconocido en España. Y eso que el coruñés reivindicó sus méritos con energía, sobre todo para avalar las solicitudes de entrada en su país al estallar la II Guerra Mundial. Aun así, no consiguió evacuar a su familia de Praga, donde corría peligro de muerte. E intentó en vano depurar responsabilidades por haber quedado enturbiada su hoja de servicios. La razón es que sirvió a la II República. Y esto hizo inútiles sus esfuerzos de acogerse a la amnistía de Franco.

Fueron algunas figuras destacadas del hispanismo checoslovaco las que, mucho tiempo después, elevaron su voz en favor de Fariña. Se trata del mencionado Polišenský y, luego, sus alumnos Vladimír Nálevka y Josef Opatrný. Apuntaron los méritos del coruñés en la puesta de largo de esta especialidad.

Realmente, fue olvidado por todos, menos por Polišenský, y sería importante hablar de ese papel de fundador. Los que se dedicaron a la Literatura, Lingüística e Historia hispánica eran en esencia sus seguidores.

10 Ibidem.

11 Josef POLIŠENKÝ, Historik v měnícím se světě [Un historiador en un mundo cambiante], Praha 2001 . 
Declaró Nálevka al autor de estas líneas en una entrevista el 7 de septiembre de 2007, poco antes de fallecer. Opatrný hizo también un llamamiento a rehabilitar su figura durante un simposio praguense ese mismo año. ${ }^{12}$

Polišenský recuerda en sus memorias que se hizo amigo del profesor gallego y su mujer, Gertrudis Hille-Neuberth, nada más llegar a Praga. A pesar de que era crítico con la minoría de habla alemana, entabló una excelente relación con Gertrudis. Ella y Fariña se casaron en la capital checa el 25 de febrero de 1933, concretamente en la Iglesia de Nuestra Señora de la Victoria, también conocida como del Niño Jesús de Praga. ${ }^{13}$ Aquí fueron bautizados los tres hijos del matrimonio: Francisco, el 26 de febrero de 1934; Pedro, el 4 de abril de 1936; y José María, el 7 de julio de 1939.

Gertrudis nació el 16 de octubre de 1905 en Velký Šenov (Gross Schönau, en alemán) y era hija de Josef Hille, un industrial de los Sudetes, y Marie Therezie Neuberth. Probablemente, la posición desahogada de la familia Hille Neuberth atenuó las estrecheces económicas de los Fariña. Los distintos domicilios praguenses, en las calles Břetislavova 18 (antiguo distrito XII), Ovenecká 89 (Bubeneč), Dobrovského 33 (Holešovice), y Vilímovská 25 (Hanspaulka), sin ser barrios exclusivos, sí que eran de un estándar de clase media acomodada.

Polišenský recuerda los agasajos culinarios de Gertrudis cada vez que les visitaba en el piso de Holešovice, junto al parque de Letná. Aquellos ricos tentempiés rompían la relación formal entre profesor y alumno. Fariña facilitaba al historiador en ciernes libros sobre la civilización hispánica, de José Ortega y Gasset o Miguel de Unamuno, obras aún poco conocidas entre los intelectuales checos. Ese trato cordial hizo que el interés inicial por la historia se ampliara a la lengua y cultura del país latino.

El académico recuerda la actividad propagandística de Fariña en favor de la república democrática, algo en lo que también participó. A la iniciativa se sumó el académico Václav Černý, que mostraba simpatías a ese régimen político sin convertirlo en patrimonio de la izquierda. Ambos colegas de la Facultad de Letras de la Universidad Carolina de Praga publicaron conjuntamente en el Kritický měsíčník, un boletín mensual de análisis literario.

Antonín Kučera, lexicógrafo y lingüista emigrado a Alemania, tuvo a Fariña como profesor particular en los años treinta. Entre los recuerdos que nos ha dejado, acentuó que el coruñés era escéptico sobre la evolución política en Checoslovaquia en 1945, ya que amenazaba con tendencias estalinistas. Fariña se mostraba, en esas conversaciones privadas, crítico sobre el sistema. De hecho, una de sus tesis era que Stalin suponía la derrota de la España republicana. ${ }^{14}$

Al margen de su postura política, Fariña contribuyó a que el hispanismo ganara rango de disciplina independiente en las cátedras de Lenguas Románicas. Esta siembra dio fruto gracias a la actividad de sus alumnos, entre los que destacaron

12 Josef OPATRNÝ, España y los países checos: simposio sobre sus lazos históricos, (Simposio del Centro de Estudios Ibero-Americanos de la Universidad Carolina, 19 y 20 de octubre), Praga 2007.

13 Matriční archiv pro Prahu 1, Praga (en adelante sólo MA), "Registro de matrimonios de la parroquia de Panna Maria pod řetězem" (1933-1939). Fueron testigos de enlace el diplomático español Francisco Agramonte y el empresario Julius Hille, familiar de la novia.

14 Entrevista con Vladimír Nálevka, 7 de septiembre de 2007. 
Josef Polišenský, el mencionado Kučera, Oldřich Bělič, Oldřich Tichý, Libuše Prokopová y Kamil Uhliř, entre otros. Fueron los continuadores del proyecto piloto del coruñés. Incluyo a Prokopová porque asistió a clases particulares de Fariña -en el piso de la calle Palackého- y porque estuvo muy vinculada a otro personaje clave en la trayectoria de Fariña: Jaroslav Kuchválek.

\section{El testimonio de Libuše Prokopová}

Al hablar de su profesor de castellano, Prokopová le recuerda "menudo, bastante pequeño y de cabello oscuro. Nada seco sino amable, y ponía mucha energía en sus clases". Así ha permanecido en su memoria, después de casi 75 años. Libuše Prokopová ${ }^{15}$ ha sido luego una de las más reconocidas filólogas del español. Autora de numerosos manuales de gramática, que fueron y siguen siendo lectura obligada para esas generaciones de checos y eslovacos interesados en la lengua de Cervantes.

Libuše Prokopová tenía entonces 26 años. Como otros muchos, se ha visto obligada a interrumpir sus estudios durante un lustro de ocupación nazi. Este contratiempo fue un varapalo para la inteligencia checoslovaca. Pero las clases por fin se reanudan, aunque en un clima que pronto se volverá hostil y enrarecido.

La joven había asistido en la Facultad de Letras de la Universidad Carolina, poco antes del estallido de la guerra mundial, al curso de español del profesor Rudolf J. Slabý (1885-1957). Era la asignatura que -como explicaremos- debía haber impartido Fariña. Merece la pena recordar quién es Slabý, que se convirtió en rival a muerte de nuestro personaje, o al menos así lo pintó el español en sus "escritos apologéticos". En 1933 Slabý publicó en Madrid Checoslovaquia: su presente, su pasado y sus relaciones con España y los países iberoamericanos. En 1940 sacó en Praga su Kapesní slovník španělsko-český a česko-španělský s výběrem výrazů amerických [Diccionario español-checo y checo-español con una selección de americanismos y voces técnicas] en edición de bolsillo.

Según Fariña, Slabý no tiene formación propiamente filológica, ${ }^{16}$ y su conocimiento del castellano procede más bien de sus correrías por el mundo. Había sido violonchelista en una orquesta de Barcelona, por lo que también se interesa por el catalán. Fariña trata de quitarle méritos académicos y afirma con desdén que Slabý era profesor de academia de comercio. Tal vez no reparó en que la formación profesional en Checoslovaquia estaba mucho más desarrollada, y que esos entes

15 En el parte de la Comunidad de Traductores se informó del fallecimiento de Prokopová, ocurrido el 7 de noviembre de 2014: "A la edad de 95 años, murió la hispanista Libuše Prokopová PhD., que fue muchos años redactora de la Editorial Orbis. Tradujo hasta mediados de los años 80, sobre todo para la revista Světova Literatura y la Editorial Odeon.

16 Archivo General. Ministerio de Asuntos Exteriores, Madrid (España) (en adelante sólo AMAEC), Archivo renovado, R-2.596/4, carta de Francisco Fariña a Gaspar Sanz y Tovar, cónsul general de España en Checoslovaquia (Praga, 12 de enero de 1940). "Es el deseo del sr. Slabý de poder entrar, gracias a la influencia de España, por la puerta falsa al profesorado de la Universidad. Él quiere ser catedrático de Literatura Española en la Facultad de Letras de la Universidad en Praga. Incapaz de hacer una obra científica adecuada, sin poseer una especialización romanista universitaria (porque tiene un doctorado que nadie sabe en qué consiste y a qué preparación se debe), él pretende entrar como Lector de Español, para hacerse después Docente y entrar después en la cátedra." 
gozaban de prestigio. Slabý se preocupa además de mejorar conocimientos. Y, con este fin, se va a España invitado por su amigo Fernando Arango, para perfeccionar los dos idiomas: castellano y catalán. Más adelante, el checo es nombrado docente de Literatura Eslava en la Universidad de Barcelona. Sabía hasta diez lenguas de la familia indoeuropea.

Fariña concede poco crédito a Slabý, pero el checo queda bastante bien parado si nos atenemos a los recortes de prensa de entonces. En un artículo del crítico literario Václav František Suk, publicado en Národní listy el 9 de julio de 1922 y titulado "Cómo se trabaja por nosotros en España", ${ }^{17}$ se dice que "se ha superado la asociación checo-gitano-bohemia". Suk recuerda las ediciones de obras checas de Božena Němcová, de sus cuentos, de los cuentos de Karel Jaromír Erben, así como de traducciones realizadas por Slabý, en concreto, la Rana princesa, publicada en 1920 en la colección Selección de cuentos para niños de la Editorial Cervantes. No hay que olvidar la fabulosa tradición de cuentos populares (pohádky, en checo), que comienza por entonces a ser compartida con España. Slabý traduce también a otros grandes literatos checos, como Aloiš Jirášek, Julius Zeyer, Karolina Světlá, Ignát Hermann, Josef Karel Šlejhar, Jaroslav Vrchlický, Svatopluk Čech y Josef Svatopluk Machar. Vertió al español y catalán casi treinta obras de autores de lenguas eslavas, entre ellos nombres célebres como Henryk Sienkiewicz, Aleksandr Pushkin, Iván Turguénev, León Tolstói y Leónidas Andréiev.

El trabajo de Slabý es considerado un "milagro en el campo de la lingüística" por la crítica literaria española, así como "la encarnación del eslavismo en España", afirma Suk. El estudioso colaboró también en la voz "Checoslovaquia" de la Enciclopedia Universal Espasa Calpe.$^{18}$ Con esta trayectoria, quizás Slabý no fuera un filólogo en estricto sentido, pero tampoco era un aficionado. Y hay que recordar que ni siquiera Fariña llegó a Praga avalado por un título de lengua, sino de historiador.

Slabý domina además el idioma de Goethe, y es autor -junto a Rudolf Grossmann- de un diccionario alemán-español, posiblemente el mejor de su género todavía hoy. Slabý también emprende la elaboración de un diccionario checo-alemán, a partir del cual proyecta un diccionario checo-español. El bombardeo aliado de Dresde al final de la II Guerra Mundial hizo que se perdieran estos materiales. Al tener Slabý un contrato con la editorial Statní pedagogické nakladatelství (Editorial Pedagógica Nacional), a su fallecimiento se busca alguien a quien encomendar la tarea, que acabó sobre los hombros de Prokopová. ${ }^{19}$

Cuando se reanudan las clases en 1945, la checa se matricula en Filología Francesa y Literatura en el Departamento de Lenguas Romances de la Facultad de Letras de la Universidad Carolina. Asiste a los cursos de Literatura Española de Václav Černý (1905-1987) y de Gramática Romance del profesor Vladimír Buben (1888-1956). A pesar de que Černý cae en desgracia con la llegada de los comunistas al poder en febrero de 1948, por no alinearse con esa ideología, es llamado

17 ÚTGM, Fondo TGM, R-Republika 1918-1937, España, caja 528.

18 Ibidem, Memoria del Comité Hispano-Eslavo, Madrid 1931.

19 Libuše PROKOPOVÁ, Španělsko-český a česko-španělský kapesní slovník [Diccionario de bolsillo Español-Checo y Checo-Español], Praha 1964. 
a esa Facultad para los exámenes de doctorado. No hay otro capaz de examinar en su especialidad. Černý, al igual que Fariña, era un hombre de baja estatura y gran energía, además de muy bromista, lo que infunde miedo a la chica. Transcribo sus recuerdos a vuelapluma tras oírlos directamente de sus labios. Evocaciones de una persona que no fue discípula directa del español en la Facultad de Letras de la Universidad Carolina, pero que asistió a sus clases particulares. Y luego asistió a clase de Kuchválek (1910-1973), con quien además le unieron lazos afectivos.

Prokopová no es ajena a los vientos de solidaridad que soplan en favor de la causa republicana española ${ }^{20}$ tras el estallido de la Guerra Civil. Se involucra en la Sociedad de amigos de la España Democrática, ${ }^{21}$ creada por la Legación española.

\section{Conflicto con el Instituto Español e Iberoamericano}

¿Cuál fue la actividad docente de Fariña en Checoslovaquia? Ya mencionamos los inicios en Brno. Lo que sucedió después tiene mucho que ver con la actividad del Instituto Español e Iberoamericano, por lo que diremos algo sobre su génesis y evolución. En 1918, al nacer el Estado checoslovaco, se fundó en Praga el Círculo Español, cuyo impulsor fue el hispanófilo y ginecólogo Jaroslav Lenz (18681955). Su papel consistió en profundizar en el mutuo conocimiento entre ambos países y en sus relaciones culturales y económicas. Si nos atenemos a las fechas, los checoslovacos fueron por delante a la hora de fomentar las relaciones económico-culturales con España, ya que la iniciativa de Menéndez Pidal, a la que aludimos al inicio, cristalizó en 1931 con la creación del Comité Hispano-Eslavo. En 1929 el Círculo Español se transformó en Instituto Español e Iberoamericano (en adelante sólo IEI), ${ }^{22}$ con cuatro secciones: cultural, comercial, social y turística. Aunó a los intelectuales más vinculados con la lengua cervantina. De esta forma, el IEI se convertirá en correa de transmisión de la Legación española para la política cultural desarrollada por el Gobierno de Madrid. Esta es la razón por la que Fariña se ve obligado a colaborar con el Instituto. Su sede administrativa y aula estaban en la Casa municipal de Praga, edificio art nouveau situado en la Plaza de la República.

20 Vladimír NÁLEVKA, Cien años de interés checo por España, (Conferencia pronunciada con ocasión de la inauguración del Instituto Cervantes de Praga, el 7 de septiembre), Praga 2005. En 1946 Checoslovaquia reconoce al gobierno español en el exilio. Las relaciones con el régimen franquista no empiezan a descongelarse hasta enero de 1958, cuando se firma el convenio monetario entre el Banco Nacional Checoslovaco y el Instituto Español de Moneda Extranjera. Este instrumento permite un fuerte aumento del comercio entre ambos países. No será hasta octubre de 1970 cuando Madrid establezca una misión consular y comercial en Praga.

21 Ibidem. Esta institución retoma la labor de su predecesor, el Comité de ayuda a la España Democrática, que entre 1936 y 1938 recibió el apoyo del gobierno checoslovaco. Praga mantuvo en ese período contacto con el gobierno republicano, le envió armas, y toleró el reclutamiento de voluntarios para las brigadas internacionales.

22 MZV, Protocolo diplomático 1918-1939, caja 80. De este instituto fue estrecho colaborador el historiador y diplomático Vlastimil Kybal, que fue años después investido con la encomienda de Isabel la Católica, y cuyas crónicas de España aparecen en la prensa checa especializada. 
Además de Lenz, de ideario conservador-monárquico, en el IEI también trabaja Slabý, "del que se decía que era muy franquista", afirmó Prokopová. Quizás por esas inclinaciones políticas, el republicano Fariña no tiene buenas relaciones con Slabý, máxime cuando este le encarga traducciones y otros trabajos sin la debida remuneración. Slabý le da a entender que su estancia en Checoslovaquia depende de los servicios que presta al IEI. Y, en el marco de esta ingrata colaboración, le manda traducir del francés Příběhy dobrého vojáka Švejka (Las aventuras del buen soldado Švejk), novela satírica del escritor Jaroslav Hašek, una de las más citadas de la literatura checa del siglo XX. El coruñés lo ve como una extorsión. Parecía que la colaboración con el IEI iba a más, ya que en 1935 Fariña es nombrado asesor cultural del Instituto, y el cargo fue renovado en 1936. Pero nada más lejos de la realidad. Se trató de una pura formalidad, ya que el español -según el mismo relatano fue consultado para ninguna actividad organizada por el IEI.

El problema es que, con el inicio de la Guerra Civil, Fariña queda en una situación incómoda. El embajador en Praga, el jurista y padre de la Constitución de 1931 Luís Jiménez de Asúa, ${ }^{23}$ denuncia al IEI por su "posición contraria a la causa del pueblo español y enteramente fascista". ${ }^{24}$ Asúa ve inviable la permanencia de Fariña en el Instituto. El gallego será el principal perjudicado por la medida, ya que la ruptura de relaciones hará que el IEI se movilice para impedir al gallego dar clase en otros lugares.

De momento, Fariña sólo tuvo que abandonar las aulas del IEI en Praga, y le quedó el trabajo en la Facultad de la Letras de la Universidad Carolina en Praga y en los lectorados de español de Brno y Bratislava. Sabemos, por la documentación de entonces, que los problemas financieros de un país en guerra hacían que se retrasaran las remesas de la Junta de Relaciones Culturales, incluidos los importes para sufragar los sueldos del profesor. Por aquella época Fariña percibía 7.000 pesetas-oro anuales, pagaderas en francos franceses. Las altas comisiones de cambio de los bancos checos hace que solicite el pago en libras esterlinas o, directamente, en coronas checoslovacas.

Para complicar aún más las cosas, Fariña cae en desgracia con Jiménez de Asúa. Haría falta un estudio detallado de los motivos, pero a la luz de la correspondencia se entrevén suspicacias en el jefe de la Legación. Al ver mermada su actividad académica, Fariña trata de buscarse valedores. Y se organiza una estancia en Madrid sin informar debidamente a Asúa, que es entonces jefe de Fariña cuando este asume el cargo de agregado cultural en la embajada.

23 Alberto RUIZ, 70. aniversario de la presentación de cartas credenciales por Luís Jiménez de Asúa. Praga 2007. El jurista Luís Jiménez de Asúa, coautor de la Constitución de 1931, fue ministro plenipotenciario de España en Praga y lideró la misión diplomática del 14 de octubre de 1936 hasta el 26 de agosto de 1938.

24 AMAEC, República, Fondo de Barcelona, RE-13575, carta de Luís Jiménez de Asúa a José Giral Pereira, ministro de Estado en Valencia (Praga, 7 de julio de 1937). 
"Si se pretende censurarme por mi viaje a España es absurdo. Allí no fui a encender el odio. Fui a estudiar por mí mismo la situación", justifica el gallego su viaje a Madrid en $1937 .{ }^{25}$

Yo sólo deseaba la mejor inteligencia entre todos los españoles; pero mi personalidad insignificante de nada servía a mi mejor deseo. En Madrid hablé sobre "La guerra y los deberes y derechos de la intelectualidad". Yo creo que fue uno de los esfuerzos más sinceros para la defensa de nuestros valores espirituales. Lo que en Madrid dije tuvo para mi verdadero peligro, porque era una cordial y enérgica rectificación. Muchas personas escondidas o en situación verdaderamente difícil [...] encontraron en mis opiniones un consuelo para su angustia. Y en todas partes he podido reconstruir el ambiente cordial, noble y generoso que constituye la nota específica de nuestra tradición y que yo no quiero que pierda nuestra España. ${ }^{26}$

Jiménez de Asúa vio aquello como una maniobra a sus espaldas. Y a espaldas de Fariña se va urdiendo otro complot, que va a dejarle aún más aislado. Con el fin de volver a ganar las simpatías de la diplomacia española, el IEI incorpora como secretario del Instituto a Jaroslav Kuchválek, que fue alumno de Fariña en la Facultad de Letras de la Universidad Carolina en Praga. De Kuchválek dirá años después, cuando Franco llegue al poder, que era un:

[...] elemento de enlace del Instituto con el sr. Asúa, socialista de izquierdas con ribetes de comunismo, antifranquista declarado y entusiasta, y que rodaba de juventud política en juventud política de izquierda y que pasa a hacer propaganda antinacionalista con el sobrino del sr. Asúa. ${ }^{27}$

Este malabarismo del IEI, con un director Slabý supuestamente franquista y un secretario Kuchválek "antifranquista declarado", fue algo que puso furioso al gallego. Fariña no ahorra en críticas contra ambos. Como botón de muestra, encontré la siguiente misiva:

Mi persecución universitaria, además de un acto de venganza del sr. Slabý porque no me ha podido ni me puede explotar, de un impulso de egoísmo de esos señores por pretender distribuirse los honorarios de mis cátedras (que ellos no saben servir), de una envidia desmedida y pueril ante la simpatía que mi vida aquí se desenvuelve a pesar de todos los enredos hispanistas; la persecución del Instituto para hacerme saltar de la Universidad es el deseo del sr. Slabý de poder entrar, gracias a la influencia de España por la puerta falsa, al profesorado de la Universidad. ${ }^{28}$

25 AMAEC, Archivo renovado, R-2.596/4, carta de Francisco Fariña a Gaspar Sanz y Tovar, cónsul general de España en Checoslovaquia (Praga, 12 de enero de 1940).

26 Ibidem

27 AMAEC, Archivo renovado, R-2.596/4, carta de Francisco Fariña a Gaspar Sanz y Tovar, cónsul general de España en Checoslovaquia (Praga, 12 de enero de 1940).

28 Ibidem. 
Un episodio de aquella época es el mencionado nombramiento de Fariña como agregado cultural de la Legación, lo que no le otorga rango diplomático, pero permite justificar un salario tras quedar privado de sus lectorados de las Facultades de Letras de las Universidades Carolina Praga y Masaryk de Brno.$^{29}$ El IEI habría logrado pues sus objetivos de hacerle "saltar". Y ahora Fariña trata de hacerse un hueco en la Legación, con el objetivo de conseguir pasaporte diplomático. De esta manera se libraría de la obligación de renovar el permiso de residencia cada dos años. Intentó conseguir, aunque sin éxito, el nombramiento de agregado de Prensa, para contrarrestar lo que considera una campaña orquestada por el IEI.

Los desencuentros de Fariña con el Instituto, que fueron continuos y afectaron a la subsistencia de la familia, tienen además en su origen motivos académicos. Desde su llegada a Checoslovaquia, Fariña alberga serias objeciones sobre el sistema del IEI, pues:

[...] ha mantenido en sus enseñanzas métodos no sólo malos, sino además insoportablemente ridículos y antipáticos [...], utilizando hasta una gramática de 1882, y dando a nuestra lengua y a nuestra cultura un ambiente imposible..$^{30}$

Este rechazo de los métodos del IEI hizo que Slabý, ${ }^{31}$ cuando tenía al gallego en la nómina del Instituto, le quisiera supervisar de cerca o tener bien atado, en lenguaje coloquial. Y esto sublevaba al español, que colaboró con el Instituto hasta el curso 1936-1937.

Otro punto de fricción fue la mencionada orientación política de Slabý que, con objeto de hacerse querer por la diplomacia española de la II República, no sólo colocó al socialista Kuchválek en la directiva del IEI, sino que -tras romper el Instituto relaciones con la Legación debido a la Guerra Civil- nombró al checo como sustituto de Fariña en sus clases. ${ }^{32}$

Kuchválek es otro de los personajes que merece unas palabras, y no sólo por su relación con Fariña. Colaboró en 1939 con Slabý en el Manual de Español de viaje, que fue editado por Orbis y del que el gallego tiene un bajo concepto y critica con ironía. Nuestro personaje concluye que:

[...] todo ese grupo no piensa más que en sus intereses personales. Y como en su casi totalidad viven parasitariamente del español no han dejado de buscar la manera ni los medios para hacerme la vida imposible..$^{33}$

29 Ibidem. Esa salida de Fariña de la universidad se produce incluso antes del cierre de los entes de enseñanza superior durante el Protectorado alemán en represalia a las manifestaciones antinazis de universitarios el 28 de octubre y el 15 de noviembre de 1939.

30 Ibidem.

31 Národní knihovna České republiky, Praga (en adelante sólo NK), Národní konzervační fond. En 1937 Slabý publica en la editorial Orbis su curso rápido de español Čech ve Španělsku a španělské Americe: Španělsky [El checo en España y América española: español].

32 AMAEC, Archivo renovado, R-2.596/4, carta de Francisco Fariña a Gaspar Sanz y Tovar, cónsul general de España en Checoslovaquia (Praga, 12 de enero de 1940).

33 Ibidem. 
Como hemos dicho, al final de todo este enredo Fariña se vio privado de sus lectorados ${ }^{34}$ en las Facultades de Letras de las Universidades Carolina de Praga y Masaryk de Brno, lo que interpretó como vulneración del fuero universitario, ya que dependía de manera directa e inmediata de los directores de los departamentos de lenguas romances, y sólo podía ser nombrado o destituido contando con su aprobación.

Como los tentáculos del IEI llegaban lejos y muy alto, hizo que "saltara" incluso del Instituto de Exportación, donde editaba una revista, y de la Vysoká Škola Obchodní (Escuela Comercial Superior). La salida de estos claustros fue ordenada por el Ministerio de Instrucción Pública, a instancias del IEI. Fariñas llega a denunciar que el Instituto ha utilizado a la Legación como palanca para lograr sus fines.

¿Qué culpa tuvo Fariña en todo esto? No lo sabemos, ya que nos falta el testimonio de la otra parte, aunque hemos tratado de exponer los méritos académicos de los checos. Sí podemos afirmar que el español era persona difícil de encasillar. Y le tocó vivir una época en la que no estar a favor suponía estar en contra. Hasta el punto que quedar en entredicho ante su propio embajador durante la Guerra Civil por criticar los desmanes de la II República. Y, después de la contienda, seguir en entredicho ante el nuevo embajador franquista por haber sido funcionario de la II República. Esto suponía ipso facto una hoja de servicios empañada.

Dicho con sus propias palabras, reflejadas una vez más en sus "escritos apologéticos”, Fariña solicitará, en una carta del 14 de enero de 1940 remitida al cónsul español en Praga:

[...] para la obra de rectificación que mi caso demanda, me permito hacer constar los hechos que siguen, esperando del llamamiento interior que en todo buen español estimula al respeto y al sentido humano de la vida: fundamento de nuestra gloriosa tradición nacional, que ha de inducir al señor Cónsul no sólo a hacer cesar mi persecución, sino también a favorecer la obra que en bien de España, con todo entusiasmo y mejor éxito, aquí he iniciado. ${ }^{35}$

Es algo que no puede continuar al estar privado de su profesión.

La "maniobra incalificable" del IEI, como Fariña la llama, dura más de un lustro. Leyendo la correspondencia, nos encontramos con un hombre acosado por las contrariedades durante los años de la Guerra Civil. Contrariedades causadas por un grupo de adversarios que podían contarse con los dedos de una mano. Al acabar la guerra, Fariña reivindica su causa ante las nuevas autoridades españolas, que el Estado checoslovaco reconoce en $1939 .{ }^{36} \mathrm{Y}$ se reafirma en su papel de hombre

34 Ibidem. Estos lectorados era exclusivamente "universitarios", es decir, sólo para los alumnos del Seminario Romanista y al que por tolerancia únicamente podían acudir las demás personas. Se distinguían así de los lectorados "libres", para los alumnos tanto de la Facultad de Letras de la Universidad Carolina en Praga como fuera de ella.

35 AMAEC, Archivo renovado, R-2.596/4, carta de Francisco Fariña a Gaspar Sanz y Tovar, cónsul general de España en Checoslovaquia (Praga, 12 de enero de 1940).

36 NÁLEVKA, Cien años. Praga reconoce de iure al gobierno del general Francisco Franco el 27 de enero de 1939 y rompe todos los contactos con los republicanos. 
perseguido. Lo hace quizás con excesiva dureza y apasionamiento. A pesar de su valía profesional, pudo descuidar la cortesía en el trato con sus colaboradores y herir sensibilidades, hasta granjearse enemistad de personas influyentes.

En medio de estas contrariedades, pudo al menos -durante unos meses de 1939retomar sus clases en la Escuela Comercial Superior, donde llegó a tener 150 alumnos matriculados. Pero, para colmo de desgracias, la escuela tuvo que cerrar por orden de los alemanes, en represalia a las protestas estudiantiles contra la invasión nazi de marzo de 1939, cuando Checoslovaquia pasó a ser país satélite del III Reich.

Este nuevo revés hace que, con una familia numerosa que alimentar, Fariña se mueva. En 1939 le llaman a Radio Praga para hacer un curso de español. "Sólo puedo decir que recibí más de 300 postales de radioyentes y vendí 1.000 ejemplares de mis cuadernos". ${ }^{37}$ Slabý mandó una carta de protesta, y solicitó que se utilizara su propio manual -aquel que Fariña tanto denostaba-, aunque sin éxito. El español siguió trabajando en el estudio de Mělník de Radio Praga hasta que las emisiones se clausuraron al finalizar la II Guerra Mundial.

Por entonces, en 1944, Fariña hacía balance de su paso por Checoslovaquia y de los méritos de su docencia frente a las autoridades españolas:

Mis cátedras han sido siempre las más frecuentadas, he tenido más de 3.000 alumnos, he rectificado los lamentables métodos de enseñanza del español y elevé la estimación de nuestra cultura y nuestros estudios..$^{38}$

\section{Una hoja de servicios empañada}

¿Por qué se justifica Fariña una y otra vez ante los representantes del nuevo régimen franquista? El gallego quiere regresar a su país, pero la situación se va complicando, aún más, a medida que avanza la guerra mundial. Al desencuentro con el IEI, con el que finaliza su colaboración en el curso 1336-1937 y que además le priva de sus lectorados en Praga y Brno, ahora se suma la crisis bélica. La Legación le ofrece el 7 de septiembre de 1939 la repatriación a España, a lo que accede con agradecimiento. Aprovecha para solicitar el visado para una niñera "aria" alemana, una joven huérfana que ha estado con ellos desde el principio. Pero Fariña prefiere quedarse de momento en Checoslovaquia por razones económicas. Días después, el cónsul Sanz y Tovar le aconseja que toda la familia permanezca en Praga. ¿Cuál es la razón del cambio de parecer?

Fariña lo descubre cuando recibe, a mitad de septiembre, su cédula de nacionalidad. En ella aparece la siguiente anotación: "inscrito en el registro de españoles culpables de hechos sancionados por la ley de responsabilidades políticas". Se queda perplejo. Además, en la misma cédula consta "sin profesión", lo que fue luego parcialmente rectificado al indicarse "profesor de español". Fue otra decepción, pues esa actividad no requería en Checoslovaquia título universitario. Se degradaba así

\footnotetext{
37 AMAEC, Archivo renovado, R-2.596/4, carta de Francisco Fariña a Gaspar Sanz y Tovar, cónsul general de España en Checoslovaquia (Praga, 12 de enero de 1940).

38 AMAEC, Archivo renovado, R-2.466/55, carta de Francisco Fariña al Director General de Seguridad en Madrid (Praga, 8 de agosto de 1944).
} 
su estatus académico y quedaba en inferioridad de condiciones para acceder a un trabajo en el futuro.

Son cuatro las solicitudes que, en enero de 1940, realiza ante el Estado español, a través del cónsul Sanz y Tovar: la concesión del pasaporte; la intermediación ante el Ministerio de Instrucción Pública checo para poder ejercer en cátedras universitarias; la exclusión del registro de responsabilidades políticas o, al menos, que se depuren esas responsabilidades; y las concesiones de los beneficios de la ley de amnistía. Ninguna de esas solicitudes fue atendida.

Vuelve a pedir pasaporte el 5 de enero de 1942, si bien la familia decide permanecer en Checoslovaquia durante toda la guerra. Además de su trabajo en Radio Praga, colabora en la escuela de directivos de la empresa zapatera Bat'a de Zlín. A sus cursos acuden alumnos como Oldřich Bělič, que más adelante destacará en la esfera de la investigación literaria, y Oldřich Tichý, dedicado a la lingüística. Ambos fundaron en 1947 los estudios hispánicos en la Universidad de Palacký en Olomouc.

Esos contactos le producen algunas satisfacciones profesionales, en medio de la decepción que sufre ante el Consulado español de Praga. Esto le lleva a acudir a otra misión diplomática: se desplaza a Berlín en mayo de 1944, pero allí tampoco tiene éxito. Ni el Ministerio de Asuntos Exteriores ni la Dirección General de Seguridad españolas se prestan a normalizar su situación.

Cuando se acerca el fin de la guerra, en agosto de 1944, Fariña teme por la "indiscutible masacre" 39 que se avecina en Praga y otras ciudades de Checoslovaquia, como consecuencia del avance de los Aliados y los rusos. En una súplica final solicita la evacuación de su familia "siendo los gastos de traslado por nuestra cuenta"; la entrada en España, aunque sólo sea para acompañar a la familia; abrir un expediente para depurar responsabilidades; y hacer constar qué personas en España y Checoslovaquia han sido los artífices de ese "trato de excepción" discriminatorio. De estas peticiones, sólo le fue concedida la primera, aunque con retraso: la evacuación, a través de Suiza, tuvo lugar en abril de 1945, un mes antes del cese de las hostilidades.

Resulta curioso que el Comité Nacional Español, un organismo paraestatal checoslovaco que entonces se encarga de buscar casa, ropa y empleo a repatriados españoles que no pueden volver a su país tras la Guerra Civil, afirma que desconoce el motivo de la salida de Fariña del país el 13 de abril de $1945 .{ }^{40}$ Se puede deducir que la familia no tenía una relación de confianza con el comité.

Tras la corta evacuación en la Confederación Helvética, la familia retorna a Praga. Fariña y su mujer figuran en una lista del Ministerio del Interior que indica que llegaron de vuelta, el 10 de noviembre de 1945, procedentes de Ginebra. En la casilla de profesión figura "lector de lengua española". ${ }^{41}$ Nada ha cambiado. Al llegar se encuentran con la casa de Hanspaulka "robada y ocupada por unos supuestos

\footnotetext{
39 AMAEC, Archivo renovado, R-2.466/55, carta de Francisco Fariña a José Félix de Lequerica Erquiza, ministro de Relaciones Exteriores (Praga, 8 de agosto de 1944).

40 ABS, SÚMV, Sbírka různých písemností, signatura S-43-16/19.

${ }^{41}$ ABS, fondo SÚMV, Odbor politického zpravodajství Ministerstva vnitra, signatura 2M: 12200/6.
} 
antifascistas" ${ }^{42}$ Por ese motivo, deben alojarse en la calle Žitná 12 , en concreto en un local de la Asociación Cristiana de Mujeres Jóvenes YWCA (Young Women's Cristian Association, en inglés). Con la ayuda de Václav Černý y otros colegas consigue una vivienda provisional y volver a la enseñanza universitaria.

\section{¿Regreso a la normalidad?}

Tras la II Guerra Mundial hay una aparente vuelta a la normalidad, aunque en un contexto distinto al que enmarcó su llegada a Checoslovaquia en 1933. Ya no tiene apoyos institucionales: ni de la Junta de Relaciones Exteriores ni de la diplomacia española. Debe luchar en solitario, avalado por sus méritos académicos. Desvinculado de la Legación española y del IEI, tiene que abrirse paso entre una maraña de "mangoneadores" e "intrigantes y malvados", como él los llama. Pero comienza un período de relativa calma.

María Štemberková explica que Fariña, nada más regresar de la evacuación en Ginebra, vuelve a sus obligaciones docentes en la Facultad de Letras de la Universidad Carolina en Praga. ¿Había logrado depurar su hoja de servicios? ¿Cuánto duraría esa rehabilitación? También la Universidad Masaryk de Brno tiene interés en que reanude la actividad, y el claustro decide que comience en el semestre de verano de 1946, aunque con una dedicación reducida de seis horas semanales. Paralelamente, Fariña comienza a impartir clases particulares en un piso de la calle Palackého. Son seis alumnos, entre ellos Prokopová, los que asisten.

Pero la bonanza dura poco. El catedrático de literatura comparada Václav Černý escribe en sus memorias que Fariña fue víctima de los comunistas checos, que pretendían hacerse con la enseñanza del Español en la Facultad de Letras de la Universidad Carolina en Praga. En una campaña urdida por el profesor Kuchválek, le acusaron de colaboración con los alemanes. ${ }^{43}$

Aquellas denuncias, explica Černý, hicieron que el asunto llegara al Gobierno republicano en el exilio, que intercedió en favor de Fariña a través del ministro para Asuntos Vascos. Gracias al apoyo de compatriotas republicanos de París y de republicanos no comunistas checos, el lector logró permanecer en la Facultad, aunque disgustado por estas maniobras. Černý afirma que Fariña "salió del país antes que los simpatizantes del febrero de 1948 pudieran liquidarle de forma más cruel" ${ }^{44} \mathrm{Se}$ refería a la fecha fatídica del 25 de febrero, cuando los comunistas se hicieron con el poder -y no lo abandonaron hasta 1989-.

Sobre ese cambio de circunstancias políticas en Checoslovaquia, Urban matiza que después del golpe de estado comunista:

Francisco Fariña, al igual que el catedrático Václav Černý y muchos otros, fue expulsado de la Universidad Carolina. Posteriormente, este abuso de los nuevos

42 Vít URBAN, Fundador de la Hispanística moderna de Praga [on-line], Radio Prague International, 20 de octubre de 2001, [consultado el 9 de octubre de 2009]. Accesible de: http://www.radio.cz/es /articulo/786.

43 Václav ČERNÝ, Paměti III (1945-1972) [Memorias III (1945-1972)], Brno 1992.

44 Ibidem. 
'todopoderosos' fue revocado y Fariña volvió a las aulas, pero ya se preparaba para un nuevo exilio. ${ }^{45}$

Černý -y esto es de agradecer porque no teníamos una valoración académica externa del español- le caracterizó como "un filólogo práctico de nivel muy bueno. Hombre de trayectoria exitosa -al menos en lo académico-, y que contribuyó indudablemente al interés por la lengua romance" ${ }^{46}$ Pero debido al desgaste que sufrió, debió confesarle a Černý que buscaba trabajo en América Latina. Sin perjuicio, eso sí, de hacer valer sus argumentos y "defenderse encarnizadamente, ser duro como un yunque y un hablador testarudo, en síntesis un gallego" ${ }^{47}$ añade el intelectual checo.

Por entonces comienzan a trabajar en la Facultad de Letras de la Carolina de Praga dos exiliados republicanos, ambos comunistas prominentes: el coronel Juan Blázquez y el general Antonio Cordón, lo que hace temblar el puesto de Fariña. Son propuestos por el ministro de Información, Václav Kopecký, hombre de ideología estalinista que asumió interinamente la dirección del Ministerio de Educación. Según Teresa Cordón ${ }^{48}$ Kopecký actuó movido por la solidaridad hacia los exiliados comunistas españoles, que estaban siendo expulsados de Francia por el Gobierno de René Preven.

Otro ejemplo vivo de español fue el coronel del ejército republicano Juan Blázquez, que nos enseñaba a pronunciar la ceceante $s$ y las canciones republicanas del año 1936. Era temperamental y divertido, y en sus clases no hacíamos novillos. Otro exiliado, el general Cordón, daba clases de Literatura Española. En realidad, nos leía utilizando un cuaderno. Hablaba bajo y nuestros conocimientos del español eran más bien pobres. Y así nos fue. Muchas veces nos dormíamos en sus clases [...].

Escribe en sus memorias Jitka Pušová, ${ }^{49}$ que dirigió después el Departamento de Relaciones Internacionales del Ministerio de Cultura.

Es interesante traer a colación los recuerdos sobre Kuchválek de esta alumna suya, que durante toda su trayectoria en la administración pública estuvo muy vinculada a América Latina. Sus impresiones son el contrapunto a las duras críticas que hizo Fariña, y de las que se hizo eco Václav Černý en sus memorias. Este escribió que Kuchválek "no tenía los requisitos mínimos para una actividad universitaria, ya que desde el punto de vista científico e intelectual era absolutamente estéril" ${ }^{50} \mathrm{La}$ labor académica del checo no dejó apenas rastro en la bibliografía y en la Biblioteca Nacional sólo se conserva una obra suya: "Estudio sobre los cambios de consonantes y vocales en el dialecto andaluz", publicado en 1951.

45 URBAN, Fundador.

46 ČERNÝ, Paměti, p. 99.

47 Ibidem.

48 Hija de Antonio Cordón y Rosa Vilas.

49 Jitka PUŠOVÁ, Vzpomínání 20 let s Latinskou Amerikou [Recuerdos de veinte años con América Latina], Praha 1997.

50 ČERNÝ, Paměti, p. 375. 
Kuchválek sí que supo hacer algo muy valioso para Pušová, y que transcendía lo meramente académico: inculcó su amor por los latinoamericanos. "Los quería, los comprendía y estaba muy a gusto con ellos", afirma la checa. Kuchválek era entonces colaborador externo del Ministerio de Información, desde donde se organizaba la propaganda del régimen. Y aconsejó a su alumna para que trabajara en las relaciones internacionales de dicho Ministerio.

Kuchválek, según el recuento de su alumna, conocía bien las civilizaciones precolombinas mexicanas y los temas de actualidad del continente americano. Estaba familiarizado con sus obras literarias. Y destacaba como cicerone durante las visitas a Praga de intelectuales y políticos latinoamericanos. Hasta el punto que en los años 50 quisieron hacerle cónsul honorario. Su vida discurría en una aparente monotonía y sin sobresaltos, pero luego se transformaba durante los paseos con el chileno Pablo Neruda, el brasileño Jorge Amado, el cubano Nicolás Guillén o el general de la revolución mexicana Heriberto Jara. "Desde entonces tuve la impresión de que había dos Kuchválek: uno checo, melancólico, cansado y enfermo; y otro español, hablador, alegre y acompañante chistoso". ${ }^{51}$ Kuchválek también venía por el hogar de Antonio Cordón, recuerda la hija del general. ${ }^{52}$

Estas impresiones de amigos, colaboradores y alumnos aportan nuevos matices sobre un personaje que hizo la vida imposible a Francisco Fariña, o al menos así lo denunció el español. Había celotipias, rivalidades, rencores y, sobre todo, un choque de mentalidades. Ninguno de los dos se apeó de burro, usando expresión castiza que indica intransigencia. Las diferencias políticas jugaron también su papel, pero pienso que no fueron determinantes. Prueba de ello es que Kuchválek fue muy querido por alumnos suyos de orientación democratacristiana. Uno de ellos es Vladimír Rejžek, que militó en la Lidová strana (Partido Popular Checoslovaco) o Partido Socialcristiano. Rejžek iba a clase al Masarykovo reálné gymnázium, un liceo de prestigio para chicos en la calle Křemencová. "Como Eaton en Inglaterra", me explicó al entrevistarle. Aquí Kuchválek impartía clases de Educación Física y Francés, y formaba a sus alumnos en el carácter. Un tipo válido como profesor de escuela secundaria, donde "nunca nos gritó, porque tenía autoridad natural", recuerda Rejžek.

Este "honrado comunista de origen humilde procedente del Sur de Bohemia", como lo describe su alumno, jamás hablaba de sus convicciones políticas. En una ocasión les planteó algo que fue decisivo en el desarrollo académico del joven y de su compañero Kamil Uhliř. "¿Qué os parece si empezamos a dar clases de español?”. Les lanzó la sugerencia en 1939, cuando cursaban el sexto grado (16 años) del liceo. Tras la respuesta entusiasta de los chicos, Kuchválek mandó la instancia pertinente al Ministerio de Educación. Y en séptimo y octavo grado comenzó a impartirles clases de español.

Rejžek realizó en 1942 los exámenes de bachillerato (maturitní zkoušky, en checo), el equivalente checo del examen estatal de selectividad. Como las universidades checoslovacas habían sido clausuradas por los nazis, el joven trabajó en fábricas,

51 PUŠOVÁ, Vzpomínání, p. 9.

52 Entrevista a Teresa Cordón, 6 de junio de 2008. 
concretamente en ČKD (Českomoravská-Kolben-Daněk) Libeň, para apoyar el esfuerzo militar en los años del Protectorado alemán. Pero mantuvo su relación con el idioma español a través del Club de los Modernos Filólogos, donde Kuchválek daba clases nocturnas.

- ¿Qué significa postizo? ¿De dónde viene esta palabra?- les preguntó una vez. La respuesta acertada de Rejžek le valió la felicitación del profesor.

- ¡Muchacho, tienes futuro en el caso de que te dediques a la lingüística!

Después de la guerra, Kuchválek entró en la Facultad de Filosofía y Letras con el grado de lector, el más bajo del escalafón. Y continuaron asistiendo a sus clases tanto Rejžek, que se especializó en Lingüística, siguiendo el consejo de su maestro, como Uhlír, orientado a la Literatura. Uhlîr se convirtió luego en uno de principales traductores de los autores argentinos J. L. Borges y J. Cortázar y del uruguayo M. Benedetti. Y tuvo que interrumpir esta actividad y dedicarse a trabajos manuales en los años 70 por haber criticado la invasión de las tropas soviéticas en agosto de 1968, la operación militar que puso fin al sueño aperturista de la Primavera de Praga.

Rejžek no entró en contacto directo con Fariña durante sus años de estudiante en la Facultad de Letras de la Carolina de Praga. Hizo sus pesquisas sobre el profesor español y las respuestas no le parecieron muy alentadoras. Le dijeron que, más que mejorar el nivel de conversación de los asistentes, Fariña estaba pendiente de sus propios problemas: que no podía encontrar piso o que había sistema de racionamiento.

En junio de 1945 Kuchválek hace una petición inesperada a Rejžek: preparar la solicitud para que la lengua española sea ascendida de categoría. No sólo que pueda estudiarse como materia optativa, sino que sea "materia de aprobación" en el currículo, como el francés. Dicha petición fue firmada por unos sesenta estudiantes y entregada a Kuchválek, que se la pasó al decano. Fue en el curso 1945/1946 cuando la lengua de Cervantes adquirió nuevo rango en la Facultad de Filosofía y Letras de Praga. Un hito histórico. Desde entonces, los alumnos de Filología española deben superar el examen final estatal (statní závěrečná zkouška, en checo).

El problema que entonces se planteó fue quién impartiría la asignatura, ya que Kuchválek no tenía doctorado. En Literatura no había problema, porque estaba Václav Černý. Al final asumió las riendas del curso el profesor Buben, mientras que Kuchválek se ocupó de la asignatura de Lengua Práctica (traducción y conversación). Y sus alumnos Rejžek, Uhlî̃ y Prokopová no cejaron hasta verle conseguir el grado académico necesario, con el trabajo ya citado sobre los dialectos andaluces.

Rejžek fue el primer alumno de la Universidad Carolina en superar el examen final de español. A la vuelta de los años sigue orgulloso de esta primicia. Y recuerda muy bien que en el tribunal de examinadores estaba su mentor.

- ¿Verdad que no me harás pasar vergüenza? -le rogó Kuchválek.

Vladimír Rejžek comenzó a dar clases en 1948 como interino, a la vez que avanzaba en su carrera universitaria. Consiguió la licenciatura en 1949 y luego perdió contacto con su maestro. "Jaroslav Kuchválek no construyó su trayectoria profesional sobre la base de ser miembro del partido", afirma. También me explicó que, por su militancia socialcristiana, trataron de echarle de la Facultad de Letras de la 
Carolina de Praga tras el golpe comunista de 1948, pero Kuchválek intercedió por él y lo impidió. ${ }^{53}$ Tampoco trató de influir en sus ideas, a pesar del atractivo panorama profesional que se le abría en caso de afiliarse a las juventudes comunistas. Esta afirmación de Rejžek contrasta con la opinión de Černý, según el cual "en la Facultad inspiraba la militancia de la juventud, a pesar de aparentar imparcialidad e independencia". ${ }^{54}$

\section{Expatriado, no exiliado}

Es momento de recapitular. El paso de Francisco Fariña por Checoslovaquia, que arranca en 1933, estuvo lleno de tribulaciones. Bastó un lustro para convencer al coruñés de lo ingrato del mundo. Como diría Elizabeth Bennet, la protagonista de Orgullo y Prejuicio:

A poca gente quiero de verdad, y de muy pocos tengo buen concepto. Cuanto más conozco el mundo más me desagrada, y el tiempo me confirma mi creencia en la inconsistencia del carácter humano, y en lo poco que se puede uno fiar de las apariencias de bondad o inteligencia.

La Bennet llegó a esta conclusión con veinte años, la mitad de los de Fariña cuando aparece por estas latitudes centroeuropeas.

Fariña, un republicano de pura cepa y sin ribetes de catolicismo formal o aparatoso, hizo en 1940 una apología de su vida, que había quedado en entredicho por su apoyo a la II República, lo que no gustó a los nuevos mandatarios del régimen franquista. Con la llegada de la dictadura en España, la hoja de servicios de Fariña había quedado empañada. Es posible que sus convicciones tampoco le dejaran regresar a su país, pero al menos quiso dejar las cosas claras. Como botón de muestra, es interesante la explicación de un viaje a Madrid en 1937, sin el apoyo del embajador socialista de turno, para impartir una conferencia que trató sobre la "defensa de nuestros valores espirituales". ${ }^{55}$ Sirve de falsilla para entender sus ideas. Allí habló de la necesidad de "reconstruir el ambiente cordial, noble y generoso que constituye la nota específica de nuestra tradición y que yo no quiero que pierda nuestra España".

Pero ni los socialistas de la II República, primero, ni los falangistas del régimen franquista, después, fueron capaces de aceptar el reto de la reconciliación nacional. Y de hacerse cargo del sentido de las afirmaciones de Fariña, que pasó a la posteridad como un incomprendido y agotó sus días en el exilio. Un exilio que no pudo ser tampoco en Checoslovaquia, que después de la II Guerra Mundial se convirtió en

53 Entrevista a Vladimír Rejžek, 20 de noviembre de 2008. En otoño de 1948 Vladimír Rejžek fue acusado por el Dr. Fried, un profesor asistente de inglés encargado de realizar "comprobaciones" en la comisión que investigaba las afinidades ideológicas de los estudiantes, para detectar tendencias burguesas. El mismo Fried huyó a Alemania dos años después.

${ }_{54}$ ČERNÝ, Paměti, p. 375.

55 AMAEC, Archivo renovado, R-2.596/4, carta de Francisco Fariña a Gaspar Sanz y Tovar, cónsul general de España en Checoslovaquia (Praga, 12 de enero de 1940). 
país-satélite de la URSS, con un régimen totalitario con el que el demócrata Fariña tampoco se identificó.

Tras abandonar Checoslovaquia en 1949, con pasaporte emitido por la Organización Internacional de Refugiados (en adelante sólo OIR) -creada por la ONU pocos años antes-, Fariña residió los últimos años de su vida en Alemania. Trabajo primero en Bonn, en los servicios exteriores del Uruguay, y luego para la Argentina. Falleció en Múnich el 3 de junio de 1955.

"Éramos expatriados, no exiliados. Si (mi padre) hubiera querido colaborar, se habría pasado al régimen. Pero era un tema de integridad moral", me explicó en una entrevista el hijo mayor, Francisco Javier Fariña Hille, que nació en Praga el 29 de octubre de 1933 y actualmente reside en Madrid.

Pero la semilla que plantó Fariña ha dado su fruto, aunque su país natal no se lo haya reconocido. Sirvan al menos de satisfacción estas líneas. Y sólo añadir que, en los momentos más inciertos de su vida en Checoslovaquia, Fariña solo pedía a España:

[...] aquellas facilidades de orden moral y de medios de difusión pedagógica (al margen de toda subvención y todo género de ingresos) para que mi labor dé aquel rendimiento y aquella valoración para nuestra cultura que yo, como español siempre alejado de toda tendencia política, he querido constantemente para nuestra patria. ${ }^{56}$

(Escrito en español por el autor)

\section{BIBLIOGRAFÍA}

ČERNÝ, Václav, Paměti III (1945-1972) [Memorias III], Brno: Atlantis, 1992.

MILLÁN-PUELLES, Antonio, El ideal universitario [on-line], Madrid 1999. Arbil.org [consultado 6 de mayo de 2021]. Accesible de: http://www.arbil.org/97idea.htm.

MIŠTINOVÁ, Anna, "Enseñanza del español en el sistema educativo checo: aspectos metodológicos y factores extra-lingüísticos", in: José María Izquierdo, Olga Juan Lázaro, Juan Pedro De Basterrechea, Montserrat Alonso, Rocío Prieto, Ana Mochón, Hyosang Lim y Werner Altmann, Actas del I Congreso internacional de FIAPE: "El español, lengua del futuro", Toledo: FIAPE y Biblioteca Virtual redELE, 2005, pp. 1-9.

NÁLEVKA, Vladimír, Cien años de interés checo por España, (Conferencia pronunciada con ocasión de la inauguración del Instituto Cervantes de Praga, el 7 de septiembre de 2005), Praga 2005.

OPATRNÝ, Josef, España y los países checos: simposio sobre sus lazos históricos, (Simposio del Centro de Estudios Ibero-Americanos de la Universidad Carolina, 19 y 20 de octubre), Praga 2007.

POLIŠENKÝ, Josef, Historik v měnícím se světě [Un historiador en un mundo cambiante]. Praha: Univerzitní nakladatelství UK, 2001.

PROKOPOVÁ, Libuše, Španělsko-český a česko-španělský kapesní slovník [Diccionario de bolsillo Español-Checo y Checo-Español], Praha: 3. vydání, Státní pedagogické Nakladatelství, 1964.

PUŠOVÁ, Jitka, Vzpomínání 20 let s Latinskou Amerikou [Recuerdos de veinte años con América Latina], Praha: Press \& Print, 1997.

RUIZ, Alberto, 70 aniversario de la presentación de cartas credenciales por Luis Jiménez de Asúa, Praga: Instituto Cervantes, 2007.

56 Ibidem. 
ŠTEMBERKOVÁ, Marie, "Oblíbený učitel studenta a doktoranda Josefa Polišenského" [El admirado profesor del estudiante y doctorando Josef Polišenský], in: Ivo Barteček - Zdeněk Šamberger (eds.), Ad honorem Josef Polišenský 1915-2001, Olomouc: Univerzita Palackého v Olomouci, 2007.

URBAN, Vít, Fundador de la Hispanística moderna de Praga. [on-line], Radio Prague International, 20 de octubre de 2001, [consultado el 9 de octubre de 2009]. Accesible de: http://www.radio.cz/es/ articulo/786.

\section{ARCHIVOS}

Ústav TGM v Praze (ÚTGM), [Archivo del Instituto Tomáš Garrigue Masaryk], Praga (República Checa).

Archiv MZV (AMZV), [Archivo del Ministerio de Asuntos Exteriores], Praga (República Checa).

Archivo del Palacio Real (APR), Madrid (España).

Matriční archiv pro Prahu 1 (MA), [Archivo del Registro Civil. Distrito Primero], Praga (República Checa).

Archivo General. Ministerio de Asuntos Exteriores (AMAEC). Madrid (España)

Národní archiv v Praze (NA), [Archivo Nacional], Praga (República Checa).

Archiv bezpečnostních složek Praha (ABS), [Archivo de las fuerzas de seguridad], Praga (República Checa).

Národní knihovna České republiky (NK), [Biblioteca Nacional de la República Checa], Praga.

\section{Breve información sobre el autor}

Correo electrónico: gmonge100@hotmail.com

Gustavo Monge (Madrid, 1967) es un periodista español residente en la República Checa desde 1991. Compagina su trabajo de corresponsal con la investigación histórica y la enseñanza. Ha publicado numerosos artículos en revistas de divulgación y especializadas sobre españoles ilustres en Bohemia y Moravia, un manual de español para la Escuela Superior de Economía (VŠE), y el libro Yo también estuve en Praga, sobre el empresariado español en el país centroeuropeo. 